the larger, more important issues are concerned, dissenters from the consensus are sometimes violently reviled and sometimes praised as heroes.

". . . geologists were unable to contemplate the collapse of the vast observational and intellectual edifice created by their predecessors. . . .

"But even more frightening are those people who wrote saying that continental drift is now an accepted fact and that Geotimes should not print views to the contrary. . . . The history of geology is replete with long-discarded theories once regarded as well-proven facts. . . .

"But if history is anything to go by, some of the objections to drift will turn out to be insuperable and will form the seeds of an improved global model of the Earth. In the meantime, it is import- ant that the objections are kept in view rather than swept under the carpet."

For "continental drift" read "organic evolution".

$$
\begin{aligned}
& \text { Yours faithfully, } \\
& \text { P. C. WRAIGHT }
\end{aligned}
$$

Department of Natural Philosophy,

Aberdeen University,

Aberdeen AB9 $2 U E$,

Scotland

\title{
Obituary
}

\section{Dr Harlow Shapley}

WITH the passing, on October 20, 1972, of Dr Harlow Shapley less than two weeks before his 87 th birthday, the world astronomical community has lost one of its outstanding leaders in the first half of the 20th century; and (by the time of his death) also one of the last survivors of its heroic age which saw the 19th century solar-system astronomy (almost) "break the barriers of the heavens"-an effort in which Shapley took a prominent part.

Born on November 2, 1885, in Nashville, Missouri, in the rural mid-west of the United States, Shapley was deflected to study astronomy almost by accident (from professional journalism), though he remained a successful writer for the rest of his life. His academic career led him through the University of Missouri (AB in 1910, AM in 1911)-where he came under the influence of Frederick $H$. Seares (1873-1964)-and subsequently to Princeton, then being rejuvenated under the new administration of President Woodrow Wilson, with young Henry Norris Russell (1877-1957) at the head of its astronomy department.

The time when Shapley came to Princeton could not have been more propitious. Shortly before, Russell embarked on a new approach to the analysis of the light curves of eclipsing variables in quest of the properties of the constituent stars. The arrival of a research student of Shapley's calibre was a godsend to the subject as well as to Russell himself ; for thousands of observations were by 1912 awaiting analysis. Russell-aided by his never-absent sliderule, and unimpeded by any excess of mathematical sophistication-was the guide; but without Shapley's energy in applications the new methods would not have got off the ground. Shapley's $1914 \mathrm{PhD}$ thesis on the orbits of 90 eclipsing binaries virtually created in one stroke a new branch of double-star astronomy.

Having received his doctorate, Shapley joined the staff of the Mount Wilson Observatory in California. Fortune smiled on him (and on astronomy) when George Ellery Hale (1868-1936) offered him a research post at one of the few institutions in the United States where such positions were available at that time ; and Shapley made ample use of his opportunity. His scientific interests shifted from eclipsing variables - a field in which he retained lasting interest, but to which he never really returned - to globular star clusters; and with their aid he made, in 1918, what was to become his greatest single contribution to science: namely, the discovery of the dimensions of our Galaxy, and of the location of its centre.

That the distribution of such clusters in the sky is highly asymmetric (most of them are situated in one hemisphere) was known long before Shapley's time ; as well as the fact that many of them contain large numbers of cepheid variables whose absolute brightness can be estimated from the periods of their light changes. Armed with this evidence, Shapley embarked on systematic study of the distribution of globular clusters in space; and found its centre to be located some 50,000 light years from us, in the direction of the galactic longitude $325^{\circ}$ in the constellation of Sagittarius. This point Shapley boldly identified with centre of our entire Galaxy; and he was indeed right. As a result of his work, our Galaxy began to emerge for what it actually is: a stellar system at least ten times as large as all earlier estimates-from Herschel to Kapteynmade it out to be ; with our Sun located eccentrically some 15 thousand parsecs from its centre.

This latter distance was, to be sure, somewhat overestimated; for by 1918 Shapley was not yet aware of the absorption of light which a concentration of gas and dust close to the galactic plane exerts on distant objects at low galactic latitudes. The role of this "interstellar fog" did not transpire more fully until the 1930s, and it diminished our actual distance from the galactic centre from 15 to about 9 thousand parsecs; but the order of magnitude of
Shapley's earlier estimate remained unaltered.

The years 1914-1921, which Shapley spent at Mount Wilson, mark, in retrospect, the high noon of his scientific life ; but Shapley did not distinguish himself only in research. Soon the world-and not only the astronomers -learned to know him as an outstanding lecturer and successful writer; in addition, Hale's example helped to develop Shapley's innate talents for administration. Small wonder that-in 1920 - Shapley was offered directorship of the Harvard College Observatory, when the latter fell vacant on the death of E. C. Pickering (1846-1919). Shapley accepted; and this observatory was to remain his academic home for the rest of his life.

Under Shapley's energetic direction, the observatory's equipment was rapidly modernized, the Arequipa Southern Station transferred to become the Boyden Station in South Africa, and domestic observational activities were relegated from the proximity of the Harvard yard to the new Oak Ridge (later, Agassiz) Station some 30 miles west of Cambridge. Both the Oak Ridge and Boyden Stations were provided with new 60-inch reflectors and (in the last decade of Shapley's directorship) also with modern Schmidts. But perhaps the greatest-and certainly the most fruitful-of Shapley's innovations was the establishment of the graduate school of astronomy as a part of the educational structure of Harvard University. This school became a great success; and a list of its graduates in the 1930s reads like a Who's Who in astronomy today.

All these activities inevitably raised considerable demands on Shapley's time, but never made him abandon active work in galactic and extragalactic research. After he left Mount Wilson, Shapley no longer had reflectors as large as those on the West Coast within his reach. His telescopes at Harvard possessed smaller apertures, but wider angular fields. It was with these that 
Shapley and his collaborators continued to explore the Magellanic clouds, to probe the spatial distribution of external galaxies; and (in 1938) discovered new dwarf galaxies in Sculptor and Fornax-discoveries which augmented the known population of the inner metagalaxy in an unexpected manner.

Then World War II came; and with it a sequence of changes the end of which is nowhere yet in sight. At its end in 1945, Shapley was 60 years of age ; and as an "elder statesman" of science he was called upon to perform many extracurricular duties - such as to preside over the American Astronomical Society, the American Association for the Advancement of Science, and the National Society of Sigma Xi, almost in succession. All these duties took much of his time from the observatory and from more creative work. As a result, the last seven years of Shapley's term of office as director of the Harvard Observatory were not, perhaps, marked by the same élan as the decade preceding them; and his observatory gradually yielded its leading position to others.

Shapley's retirement from directorship in 1952 (he continued to serve as research professor until 1956) brought to a close an era which kept Harvard Observatory in the forefront of astronomical progress for 75 years under the administration of two outstanding directors-a record unequalled in the annals of astronomy. Unlike his predecessor, E. C. Pickering, who died in office, Shapley survived his retirement for another 20 years; and saw the directorship of his observatory change hands no less than three times. He continued to be active as a lecturer and author for some time after 1956 ; but his creative powers slowly waned; and he died peacefully on October 20 of this year in Boulder, Colorado, while on a visit to his son. $\mathrm{He}$ is survived by his wife Martha Betz Shapley-his faithful col- laborator already from the Princeton days, and as gracious a hostess as ever presided over the social life of any observatory, keeping her own and no small scientific abilities largely under a bushel-and five children, all of whom have been active in further development of science. Moreover, Shapley's talents as a scientist and writer are already in evidence among his grandchildren as well.

Harlow Shapley was an outstanding man of his time-astronomer, educator, author, orator, as well as man of affairs. Some of his gifts, displayed prominently in the course of his life, may gradually fall in oblivion as those of us who knew him in his prime may no longer be here to remember; and dust may settle on some of his work, or on many honours bestowed upon him by his contemporaries. But one title to fame will never tarnish-Shapley's discovery of the centre of our Galaxy, and of our position within it.

\section{Announcements}

\section{University News}

Professor G. Born has been appointed to the Sheild chair of pharmacology in the University of Cambridge, in succession to Professor A. S. V. Burgen.

Dr R. D. Guthrie, University of Sussex, has been appointed a foundation professor and chairman of the School of Science at the new Griffith University, Queensland.

Professor J. G. Ramsay has been appointed professor of earth sciences in the University of Leeds.

Dr J. R. A. Pearson, University of Cambridge, has been appointed to the chair of chemical engineering at Imperial College, University of London.

Dr G. R. Dickson, principal of the Royal Agricultural College at Cirencester, has been appointed to the chair of agriculture at the University of Newcastle upon Tyne.

\section{Miscellaneous}

The Tsiolkovskii gold medal for 1972 has been awarded to Mstislav V. Keldysh, president of the Soviet Academy of Sciences, for his "contributions to the working out of scientific problems connected with the exploitation and use of outer space".

Dr Christian de Duve of the University of Louvain and the Rockefeller University has been awarded the Dr H. P. Heineken-
Prijs for 1973, for his research on lysosomes, peroxisomes and carbohydrate metabolism.

The following Royal Society medals have been awarded by the President and Council of the Royal Society: The Copley medal, to Sir Nevill Mott, University of Cambridge and Imperial College, London; The Rumford medal to Dr B. J. Mason, Meteorological Office; The Davy medal to Professor A. J. Birch, Australian National University; The Darwin medal to Dr D. Lack, Edward Grey Institute of Field Ornithology, Oxford; The Buchanan medal to Sir Richard Doll, University of Oxford; The Hughes medal to Dr B. D. Josephson, University of Cambridge; The Leverhulme medal to Dr J. B. Adams, Cern.

\section{HOW TO BUY NATURE}

Volumes start in January, March, May, July, September and November, but subscriptions may begin at any time. The direct postal price per subscription is:

12 MONTHS (52 issues per title)

\begin{tabular}{|c|c|c|}
\hline & $\begin{array}{c}\text { Surface mail } \\
\text { UK and } \\
\text { worldwide }\end{array}$ & $\begin{array}{l}\text { U.S.A. and } \\
\text { Canada }\end{array}$ \\
\hline Nature (Friday) & $£ 16$ & $\$ 48$ \\
\hline $\begin{array}{l}\text { Nature }+ \\
\text { Nature Physical Science }\end{array}$ & $\mathbf{f 2 4}$ & $\$ 83$ \\
\hline $\begin{array}{l}\text { Nature }+ \\
\text { Nature New Biology }\end{array}$ & $£ 24$ & $\$ 83$ \\
\hline All three editions & $£ 29.50$ & $\$ 108$ \\
\hline Annual Index & £1 & $\$ 3$ \\
\hline
\end{tabular}

(Charge for delivery by air mail on application)
Editorial, Advertising and Publishing Offices of NATURE

MACMILLAN JOURNALS LIMITED 4 LITTLE ESSEX STREET, LONDON WC2R 3LF

Telephone Number: 01-836 6633. Telegrams: Phusis London WC2R 3LF Telex 262024

MACMILLAN JOURNALS LIMITED

711 NATIONAL PRESS BUILDING

WASHINGTON DC 20004

Telephone Number : $202-737$ 2355. Tele火 64280

International Advertisement Manager PETER R. KAVANAGH

MACMILLAN JOURNALS LIMITED

4 LITTLE ESSEX STREET, LONDON WC2R 3LF

Telephone Numbers: UK 01-836 6633. USA 202-737 2355

Subscription Department

MACMILLAN JOURNALS LIMITED

BRUNEL ROAD, BASINGSTOKE, HANTS RG21 2XS

Telephone Number: Basingstoke 29242

Classified advertisements

T. G SCOTT \& SON, LIMITED

1 CLEMENT'S INN, LONDON WC2A 2ED

Telephone Number: 01-242 6264/01-405 4743

Telegrams: Textualist London WC2A 2ED

Registered as a newspaper at the Post Office

Copyright (C) Macmillan Journals Limited, December 151972 